\title{
16 COMMUNICATION SKILLS FOR ADVANCE CARE PLANNING AT END-OF-LIFE
}

10.1136/bmjspcare-2011-000053.16

HCampbell1, SLillyman², PNicholson', J Jisher ${ }^{3}$ 1StRichards Hospice, Worcestershire, UK; ${ }^{2}$ University of Worcester, Worcestershire, UK; ${ }^{3}$ St Michaels Hospice, UK

A total of 44 one day advance care planning (ACP) communications workshops were developed and delivered across two counties to health and social care practitioners Band 5 and above. This collaborative project between two Hospices and a University aimed to develop knowledge, skills and confidence in ACP discussions underpinned by national and local initiatives and policy and the evidence base.

Satisfaction with the programme was excellent with $98 \%$ of participants very satisfied/satisfied that the programme was clinically relevant. There were post programme increases in confidence in exploring patient cues, structuring an ACP discussion and identifying patient \& relatives concerns.

The workshops also highlighted areas for further development in more general communication skills including identifying and following through cues and use of questions and silence.

The structure of these workshops has since been used for the development of other local programmes addressing ACP and dementia.

However recommendations from this evaluation would suggest that further communication skills training prior to the application to ACP discussions would facilitate conversations taking place particularly in getting conversations started. 